Program Profile

\title{
University of Michigan's Sustainability Scholars Program: Empowering Leaders
}

\section{Mike Shriberg, PhD, Sarah Schwimmer, and Lindsey MacDonald}

\section{Introduction}

The Graham Sustainability Scholars Program at the University of Michigan (U-M) has one core mission: to empower future sustainability leaders. In addition to earning an academic credential (similar to a certificate), most students report that the program becomes a defining experience intellectually and socially. "Being a Scholar has shaped my college experience. Until the Graham program I was sort of aimlessly trying to find my path, but now I feel directed and ready to take on the world's problems," explained a 2013 graduate. Now entering its fifth year, the program is designed explicitly to use the best practices from both the literature and the field to build sustainability leaders. These practices are encapsulated in our recent study, ${ }^{1}$ which reviewed 50 sustainability leadership programs by analyzing online program materials and interviewing 20 program directors who represent a diversity of sustainability leadership programs. These results will be referenced throughout this program profile to compare and contrast the Graham Sustainability Scholars Program with other leading programs in the field.

\section{Empowering Sustainability Leaders}

U-M prides itself on producing graduates who are "the leaders and best" (our unofficial motto)-alumni who go out into the world and make a difference. Building sustainability leaders poses unique challenges to this mantra, challenges that have given U-M, and institutions across the nation, reason to reconsider how to train the next generation of leaders. Successfully preparing students for sustainability leadership poses a particularly difficult challenge due to the "wicked" nature of environmental issues. "Wicked" problems are characterized by uncertain facts, conflicting values,

Graham Sustainability Scholars Program, University of Michigan, Ann Arbor, Michigan. high-stakes decisions, and a sense of urgency, and they require an extended peer community for resolution. ${ }^{3}$ The wickedness of environmental and interrelated social problems, coupled with the difficulties of defining sustainability and identifying clear solutions, requires institutions of higher education to cultivate a specific set of skills and knowledge in order to prepare students for leadership opportunities.

To rise to the challenge and meet the increasing demand among students, institutions of higher education are developing specialized sustainability leadership programs at a very rapid and increasing rate. At $\mathrm{U}-\mathrm{M}$, this effort has been spearheaded by the Graham Sustainability Institute, which was founded in 2006 and launched the Sustainability Scholars program in 2010. In the second semester of their sophomore year, approximately 25-35 students are selected from a highly competitive pool of applicants (mean GPA of 3.67) with diverse academic backgrounds for this supplemental

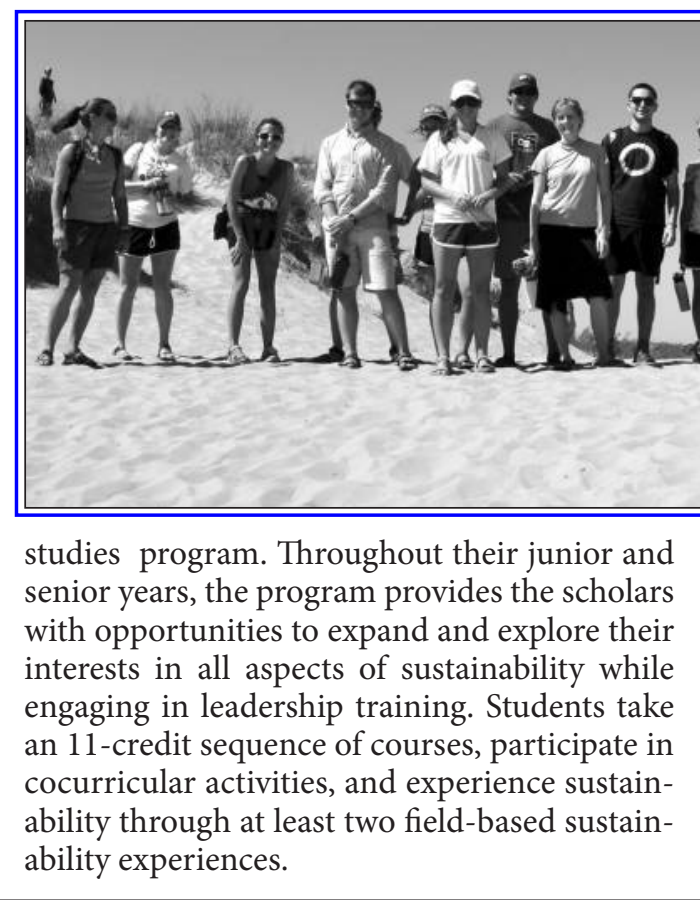

Now entering its fifth year, the program is designed explicitly to use the best practices from both the literature and the field to build sustainability leaders. 


\section{Experiential Learning}

The Graham Scholars Program incorporates at least two different types of formal experiential learning, as well as multiple informal methods. Sustainability and the Campus, a required course, is centered around a group project in which students engage in staff-sponsored sustainability projects across the U-M campus. Students directly apply principles of leadership and environmental change in a real-world setting, working with professional staff who have various constraints and opportunities. ${ }^{4}$ As part of this course, student teams have created an online sustainability map for the university; implemented a vegetable garden at the outdoor program's gear rental center, which has blossomed into a campus farm; and built partnerships between University Housing and the City of Ann Arbor, among many other successful initiatives.

The other formal experiential component is a field experience in which students participate in immersive learning throughout the world. Students can choose from a range of fieldbased courses offered by U-M, find courses offered by other institutions, or create their own field-based independent study. For example, U-M offers field-based sustainability courses in Detroit (focused on sustainable communities), Wyoming (focused on energy), Kenya (focused on sustainable land use), Costa Rica (focused on eco-tourism), New Zealand (focused on human/nature interactions), and elsewhere. Students have joined programs in Iceland, Germany, Hawaii, Australia, Fiji, and more. They have also created independent studies in Brazil, France, China, Uganda, and many other locations. As part of this field experience, students receive up to $\$ 3,000$ to implement one of these choices. This program component is frequently mentioned as the most valuable part of the program and is a primary selling point for recruitment. One student recounts: "The field experiences were the most important part to me. I was able to learn more about myself, and how I wanted my lifestyle to be when I left the university. It made me focus on goals that I have for myself in the short- and long-term future."

Although they vary significantly in emphasis, resources, and approach, project-based and field-based learning requirements are key components of more than half $(60 \%)$ of all sustainability leadership programs (see Table 1). ${ }^{1}$ Examples include working with local nonprofits and businesses, community gardens, developing countries, and student organizations. Some programs have a common experience; others have a requirement that can be fulfilled in multiple ways. The common thread is that the learning is experiential and project-based.

\section{Interdisciplinary and Systems Thinking}

The Graham Sustainability Scholars Program selects students who are high achieving and from diverse disciplinary backgrounds. For example, in the current cohort, students represent at least 26 different majors or minors. Developing interdisciplinary understanding is one of the top program values and the methodology to link these disciplines is systems thinking, which is taught via interactive activities, hands-on projects, and classic readings in the field (e.g., Donella Meadows' Thinking in Systems). The Sustainability and the Campus course begins with a series of systems-thinking simulations, as does the leadership retreat to launch the program. The junior seminar is oriented around systems thinking, using a casebased methodology to analyze key issues from multiple perspectives through the lens of sustainability. The overriding goals are not just for students to gain a greater appreciation of how different people would approach these complex issues, but also to provide a mental model for linking diverse perspectives and seeing the big picture. This programmatic value appears to be well received: Systems thinking is consistently listed as one of the top three skills gained from the program in our exit surveys. At the culmination of the program one student reflected, "I have gained a more holistic perspective and multidisciplinary way of thinking."

Many other colleges and universities (42\%) highlight systems thinking as a focal area of their programs (Table 1), but specific approaches vary. For some programs, systems thinking is the lens through which many topics are discussed, while for others there are specific courses or seminars dedicated to training in systems thinking.

\section{Defining Sustainability}

Media and politicians often simplify environmental and social issues, casting them all as black or white, while Michigan's program emphasizes the complexity of sustainability in all scales of grey. Encouragingly, students' definitions of sustainability evolve significantly during their time in the program (Figure 1). At the beginning, student definitions are relatively simple, with a focus on environmentalism and resource conservation. By the end of the program, students define sustainability in a more complex way, integrating socially oriented

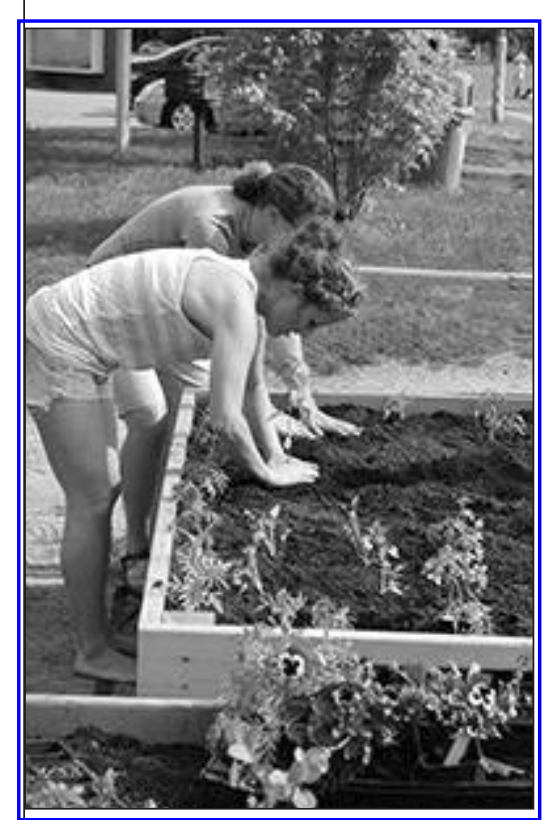

Students create a vegetable garden as part of the "Sustainability \& the Campus" course.

At the beginning, student definitions are relatively simple, with a focus on environmentalism and resource conservation.

By the end of the program, students define sustainability in a more complex way. 
Figure 1. Students' changing perceptions of sustainability

When defining sustainability leadership

in their exit surveys, students used terms like "change agent" and "resilient," which were not seen in the entry survey. In the words of one student: "Sustainability leadership is addressing issues from a holistic view, understanding the perspectives of all stakeholders involved."

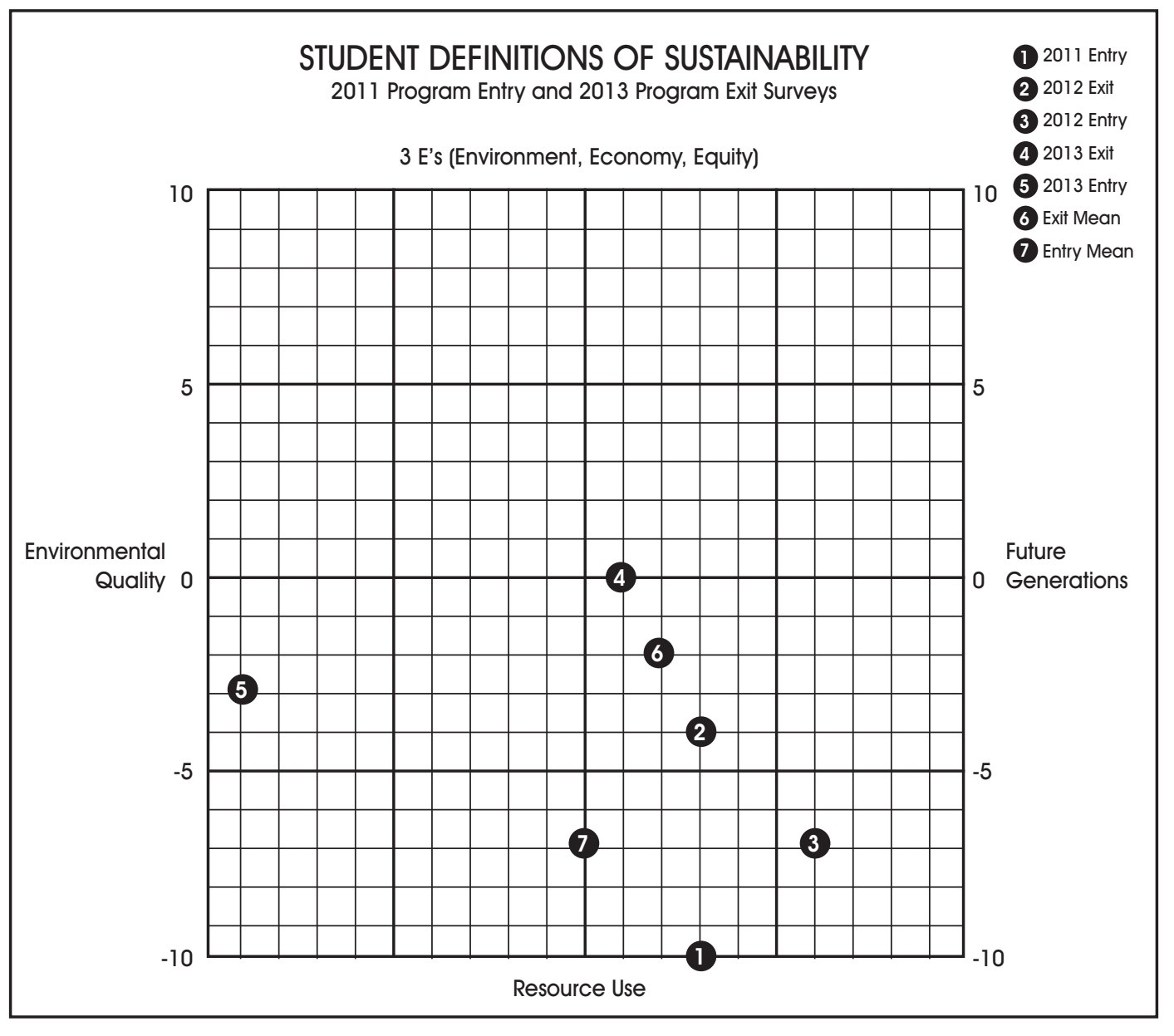

approaches with discussions of the triple bottom line and accounting for future generations. This transition happens both because the program explicitly focuses on the multiple and contested meaning of sustainability in discussions and coursework as well as via the informal interactions between students with different perspectives. For example, it is hard for a business student's sustainability perception not to change when he or she has been engaged in a deep conversation over time with a student in the School of Music, Theater and Dance.

This transition is very consistent with the goals of sustainability program leaders around the country. Interviewees discussed social, economic, and environmental sustainability. ${ }^{1}$ They talked about moving beyond sustaining to working toward a better world, about the importance of social justice components being part of the definition, about being change agents, and about improving the quality of life. This more complex definition is likely influencing the views that students take away from the programs.

\section{Leadership Approaches}

While traditional leadership theory and training often focus on one leader taking a team of people from one place to another, U-M's program encourages a vision of leadership that is relational and situational as opposed to positional and hierarchical. The acquired skill listed most frequently by students at the end of the program was an understanding of leadership methods. With a focus explicitly on leadership methods in the senior seminar as well as in discussions and activities, the student's perceptions of leadership changed throughout the program. After beginning with a transactional or transformational leadership view, as is standard in popular leadership books as well as many business schools, the students' views evolved to a more systemic, relational viewpoint. When defining sustainability leadership in their exit surveys, students used terms like "change agent" and "resilient," which were not seen in the entry survey. In the words of one student: "Sustainability leadership is addressing issues from a holistic view, understanding 
the perspectives of all stakeholders involved. ... Sustainability leadership requires motivation, visionary ideas, not getting bogged down with all the negative news, celebrating achievements no matter how small, and not 'reinventing the wheel' when it isn't necessary.”

The program devotes significant attention to leadership self-reflection, using sustainability leadership theory and the student's own experiences and vision to guide self-analysis and critique. Much of what the students learn does not come from a lecture setting, but from guided personal reflection and peer-to-peer learning. In one exit survey, a student indicated this sentiment by saying: "I have a much better idea of how I view myself as a leader." Working within the assumption that there is no one right way to lead for sustainability, students are encouraged to reflect on their leadership tendencies and how they fit into sustainability challenges.

Program directors around the country have discussed building "change agents," and the value of "process," "collaboration," and "engagement" when prompted about their leadership theories, ${ }^{1}$ and a focus on selfreflection is common in sustainability leadership programs. These leadership programs tend to assume a base knowledge in sustainability topics, and therefore spend more time delving into the complexities of personal leadership styles and self-reflection. These programs, unlike the U-M undergraduate program, are more often geared toward a graduate or professional audience. Perhaps a function of the nature of some undergraduate programs is to focus on building a baseline of sustainability knowledge, compromising some of the leadership self-reflection components in the process.

\section{Communication Skills}

Effective communication is a top skill cited for effective sustainability leadership by leaders of sustainability leadership programs across the country. The Graham Sustainability Scholars Program emphasizes persuasive communications throughout the curriculum and cocurricular activities. When students were asked in exit surveys what specific skills they had gained, communication skills was the second-most frequently named. This included comments on collaborative methods, public speaking, communicating outside of the "environmental bubble," and working with diverse people. One outgoing student reported having "the ability to better explain sustainability to others and describe how it can be applied to a range of projects and professions."

\section{In Brief.}

Program Duration

Credits

\begin{tabular}{|c|c|}
\hline & $\begin{array}{l}\text { supplemental studies designation } \\
\text { on transcript }\end{array}$ \\
\hline Seminars & $\begin{array}{l}\text { Interdisciplinary Thinking for } \\
\text { Sustainability; Sustainability Leadership } \\
\text { Development }\end{array}$ \\
\hline Off-Campus Field Experience & $\begin{array}{l}\text { Selected from list of approved courses, } \\
\text { creation of independent study, or } \\
\text { petition for course approval from U-M } \\
\text { or other college/university }\end{array}$ \\
\hline On-Campus Field Experience & $\begin{array}{l}\text { Completed through ENVIRON 391: } \\
\text { Sustainability and the Campus }\end{array}$ \\
\hline Sample of Cocurricular Activities & $\begin{array}{l}\text { Orientation retreat; Challenge Program; } \\
\text { Coffee with Practitioners; Dinner and } \\
\text { Documentary nights; winter ski retreat; } \\
\text { holiday celebration; graduation } \\
\text { celebration; informal dinners; networking } \\
\text { with speakers on campus }\end{array}$ \\
\hline
\end{tabular}

Sixty-percent of program directors that we interviewed discussed effective communication as a critical outcome of their program. Similar to course content at U-M, in this category were skills including "stakeholder engagement, negotiating power bases, interaction between participants, coalition building, communicating one's own story, relationship establishment, facilitation, managing multiple perspectives, articulating a cause, negotiation skills, and public speaking."

\section{Conclusion}

U-M's approach to empowering future sustainability leaders through the Graham Sustainability Scholars Program aligns well with the dominant goals and methods of sustainability leadership programs across the country. According to students, the key program components are: the use of a cohort approach, the focus on interdisciplinary and systems thinking as well as experiential education, skills building in effective communication, and the use of self-reflection on the meaning of leadership and sustainability. This combination is setting
The program devotes significant attention to leadership self-reflection, using sustainability leadership theory and the student's own experiences and vision to guide self-analysis and critique. 
The student response has been exceedingly positive, with the Sustainability Scholars Program often becoming the dominant force in their intellectual and social development. students up to effectively tackle "wicked" problems with both confidence and humility. The student response has been exceedingly positive, with the Sustainability Scholars Program often becoming the dominant force in their intellectual and social development and helping them achieve U-M's goal of empowering the "leaders and best." With the pressing need to develop leaders for sustainability at all levels around the world and with sustainability leadership programs blossoming in many locations, this approach may offer lessons for other colleges and universities.

\section{References}

1. Shriberg M, and MacDonald L. Sustainability leadership programs: Emerging goals, methods and best practices. J Sustain Educ 2013;5.

2. Shriberg M. Sustainability leadership as 21st century leadership. In Gallagher DR (ed.), Environmental Leadership, vol. 2: A Reference
Handbook. Sage Publications, Los Angeles, 2012, pp. 469-480.

3. Gough C, Castells N, and Funtowicz S. Integrated assessment: An emerging methodology for complex issues. Environ Modeling Assess 1998;3:9-29.

4. Shriberg M, and Harris K. Building sustainability change management and leadership skills in students: Lessons learned from "Sustainability and the Campus" at the University of Michigan. J Environ Stud Sci 2012;2(2):154164.

Address correspondence to:

Mike Shriberg, PhD

Graham Sustainability Institute

University of Michigan

625 E. Liberty Street, Suite 300

Ann Arbor, MI 48104

E-mail:mshriber@umich.edu

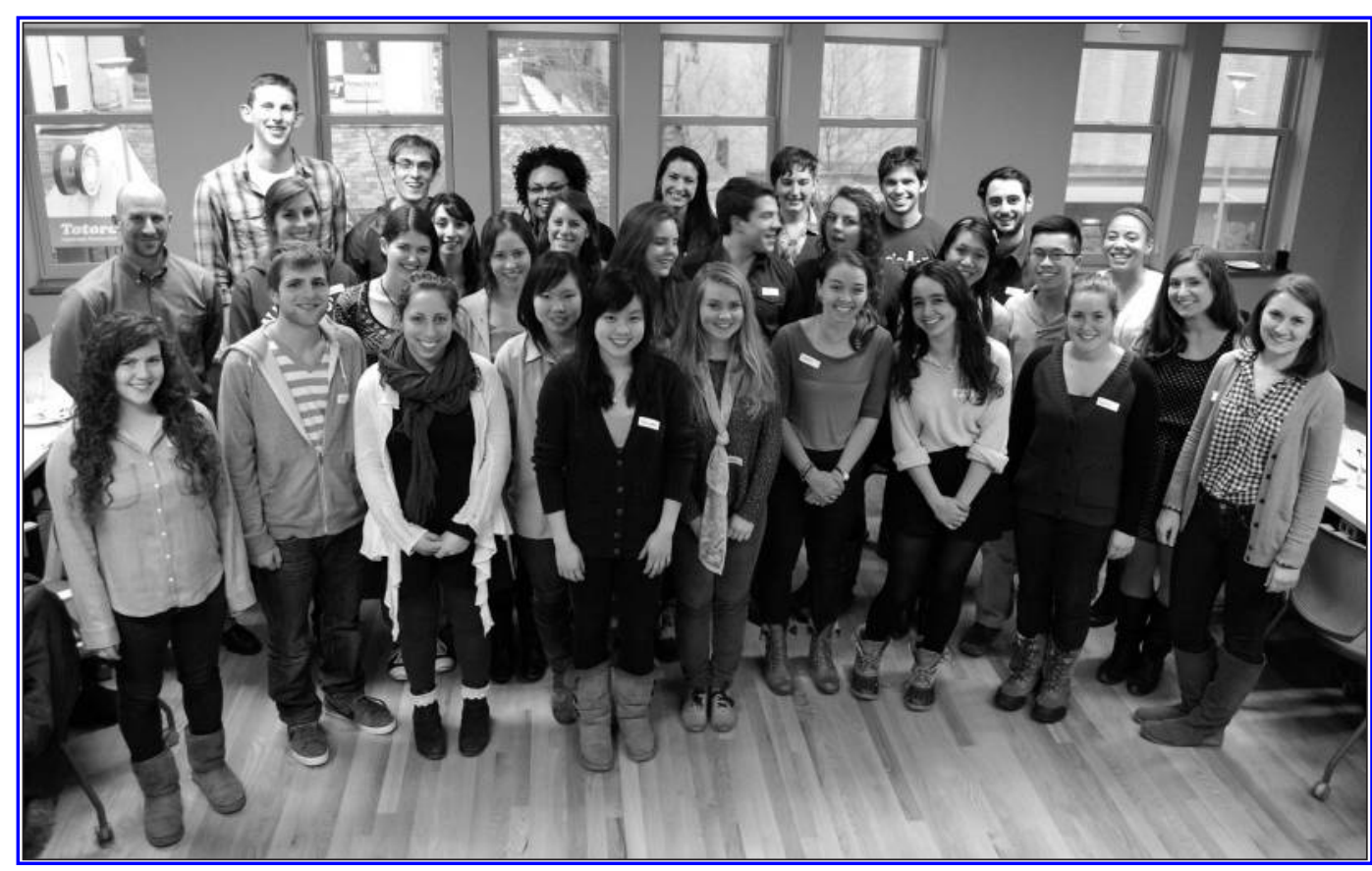

New cohort of Graham Sustainability Scholars in 2013 